\title{
Sorção, degradação e lixiviação do inseticida tiametoxam em dois solos de Mato Grosso do Sul
}

\author{
$\overline{\text { Rômulo P. Scorza Júnior }{ }^{1} \& \text { Renê L. O. Rigitano }}$
}

\section{RESU MO}

Informações sobre o comportamento ambiental de agrotóxicos são necessárias para a avaliação de sua periculosidade ambiental. O bjetivou-se, neste trabalho, determinar a sorção e a degradação do inseticida tiametoxam em duas profundidades $(0-30$ e 50-70 cm) de dois solos agrícolas do Mato Grosso do Sul, e avaliar sua lixiviação e dissipação no campo. Perfis de concentração do tiametoxam foram determinados até $100 \mathrm{~cm}$ de profundidade durante o período de 2007, 2008 e 2009. Os baixos valores da constante de equilíbrio de Freundlich obtidos para o tiametoxam mostram, em ambos os solos e profundidades, sua baixa afinidade pela fase sólida dos solos. A degradação do tiametoxam revelou-se bastante lenta, nos dois solos e profundidades, com valores de meia-vida entre 96 e 618 dias. Já no campo, observouse uma rápida dissipação do tiametoxam, logo após a aplicação. A lixiviação do tiametoxam ficou restrita aos $50 \mathrm{~cm}$ de profundidade para ambos os solos, indicando baixo potencial de contaminação da água subterrânea nos solos estudados.

Palavras-chave: comportamento ambiental, agrotóxicos, dissipação

\section{Sorption, degradation and leaching of the insecticide thiamethoxam in two soils of Mato Grosso do Sul}

\begin{abstract}
Information about environmental behaviour of pesticides is needed to assess their risks. This work had the aim to determine sorption and degradation of the insecticide thiamethoxam in two depths (0-30 and $50-70 \mathrm{~cm}$ ) of two agricultural soils in the State Mato Grosso do Sul, Brazil, as well as to evaluate its leaching and dissipation in the field. Thiamethoxam concentration profiles until $100 \mathrm{~cm}$ depth were obtained during the period of 2007, 2008 and 2009. The low values of Freundlich coefficient for equilibrium of thiamethoxam for both soils and depths show its low affinity with the soil solid phase. Thiamethoxam degradation in both soils and depths was quite slow, with half-lives between 96 and 618 days. In the field, a fast thiamethoxam dissipation was observed just after application. Thiamethoxam leaching was restricted to $50 \mathrm{~cm}$ depth, indicating low potential to contaminate groundwater in the studied soils.
\end{abstract}

Key words: environmental behaviour, pesticides, dissipation 


\section{INTRODUÇÃO}

Comumente, os agrotóxicos são aplicados diretamente no solo ou sobre as plantas. Mesmo quando aplicados sobre as plantas, parte significativa da dose aplicada acaba chegando ao solo (Chaim et al., 1999) ficando sujeitos à ação de diversos processos que governam seu comportamento ambiental. O conhecimento do destino ambiental dos agrotóxicos é essencial no processo de avaliação do risco de sua periculosidade ambiental. Assim, torna-se de fundamental importância o conhecimento dos processos envolvidos na interação dos agrotóxicos com o solo, com o objetivo de minimizar os efeitos negativos que seu uso possa causar ao meio ambiente e, sobremaneira, aos recursos hídricos (Bergström et al., 2011; Pinheiro et al., 2011). Os principais processos responsáveis pelo destino ambiental de agrotóxicos no solo são a sorção, a degradação, o escoamento superficial e a lixiviação (Scorza Júnior, 2006).

O tiametoxam (3-(2-cloro-tiazol-5-ilmetil)-5-metil-[1,3,5] oxadiazinan-4-ilideno-N-nitroamina) é um inseticida sistêmico do grupo dos neonicotinóides, utilizado para o controle de pragas nas culturas de café, soja, cana-de-açúcar, citros e outras, por meio de pulverização sobre as folhas, incorporação ao solo e tratamento de sementes (Andrei, 2005). Devido às suas características físico-químicas (baixa sorção ao solo e elevada solubilidade em água), o tiametoxam apresenta alto potencial de contaminação ambiental, principalmente por meio de lixiviação (Banerjee et al., 2008). Alguns estudos sobre a degradação, sorção e lixiviação do tiametoxam nas condições edafoclimáticas brasileiras, foram realizados mostrando alta persistência e intensa lixiviação nos solos. Urzedo et al. (2006a,b) estudaram a sorção e degradação do tiametoxam em solos da região de Lavras, $\mathrm{MG}$, e constataram que este foi fracamente adsorvido no solo, além de apresentar alta persistência, com valores de meia-vida entre 117 a 301 dias. Castro et al. (2008) estudaram a lixiviação do tiametoxam durante dois anos em um Latossolo Vermelho Acriférrico típico e em um Argissolo Vermelho Amarelo Distrófico na região de Lavras, MG, utilizando lisímetros no campo, sem vegetação e com aplicação no início do período chuvoso. Como resultados, observaram uma intensa lixiviação nos dois solos avaliados, com valores de resíduos lixiviados entre 17,8 e $56,7 \%$ da dose aplicada abaixo de $0,45 \mathrm{~m}$ e entre 0,17 e 12,6\% abaixo de 1,8 $\mathrm{m}$ de profundidade.

Estudos sobre o comportamento ambiental do tiametoxam nas condições brasileiras foram realizados em laboratório e lisímetros. Estudos em condições de campo devem ser preferidos aos de laboratório, em virtude (i) da maior semelhança às condições ambientais em que serão usados; (ii) da possibilidade de se inserir o componente planta na avaliação e (iii) integração dos processos de lixiviação e degradação que, em geral, são estudados separadamente nos estudos de laboratório. Com relação às vantagens de estudos de lixiviação a campo tem-se, quando comparados aos de lisímetros, a possibilidade de realizar amostragens dos perfis de concentração do solo, monitorar os resíduos de agrotóxicos na água subterrânea e evitar efeitos de borda como, por exemplo, o transporte preferencial de agrotóxicos nas paredes dos lisímetros (Verschoor et al., 2002).
Este trabalho teve como objetivos avaliar a sorção e degradação do inseticida tiametoxam em duas profundidades de um Latossolo Vermelho Distroférrico típico de textura muito argilosa e um Latossolo Vermelho Distrófico típico de textura média em Mato Grosso do Sul, e avaliar a lixiviação e dissipação em condições de campo. Essas informações sobre o comportamento ambiental do tiametoxam nas condições edafoclimáticas avaliadas, são de grande importância para avaliação do potencial de contaminação dos recursos hídricos, sobretudo a água subterrânea; mais ainda, essas informações poderão ser usadas para o teste de simuladores de lixiviação de agrotóxicos em solos brasileiros. Atualmente, esses simuladores são ferramentas importantes na avaliação da periculosidade ambiental de agrotóxicos nos EUA (Farenhorst et al., 2009) e na Comunidade Europeia (Boesten, 2007) e poderão ser usados em breve pelas autoridades brasileiras.

\section{Material E MÉTODOS}

Os experimentos de lixiviação foram realizados em duas áreas experimentais de $900 \mathrm{~m}^{2}$ (30 x 30 m) da Embrapa Agropecuária Oeste, localizadas nos municípios de Dourados (22 $12^{\circ}$ ' 26" S;

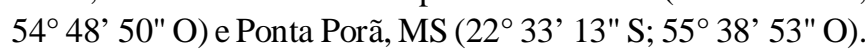
Cada área experimental foi dividida em quatro quadrantes cada uma contendo 25 subparcelas de $9 \mathrm{~m}^{2}$ ( $\left.3 \times 3 \mathrm{~m}\right)$. O solo da área em Dourados é classificado como Latossolo Vermelho Distroférrico típico de textura muito argilosa e o de Ponta Porã como Latossolo Vermelho Distrófico típico de textura média (Santos et al., 2006). Os atributos químicos e físicos das diferentes camadas dos solos são mostrados na Tabela 1 . O período experimental compreendeu de 21/11/2007 a 8/5/2008 na área de Dourados e de 19/12/2008 a 23/4/2009 na área de Ponta Porã. Em ambas as áreas foi utilizada a cultivar de soja BRS 240, com datas de plantio em 21/11/2007 para Dourados e 11/12/2008 para Ponta Porã. A aplicação do tiametoxam ocorreu no dia 04/12/2007 em Dourados e no dia 19/12/2008 em Ponta Porã, utilizando-se uma dose equivalente a $282 \mathrm{~g}$ i. a. ha ${ }^{-1} \mathrm{de}$ tiametoxam, em ambas as áreas. Para aplicação, utilizou-se um pulverizador acoplado ao trator com uma barra de $14 \mathrm{~m}$ e bicos do tipo leque (Jacto ${ }^{\circledR}$ AXI-TDIN 120-03) espaçados $50 \mathrm{~cm}$, sendo a vazão de $280 \mathrm{~L} \mathrm{ha}^{-1}$ na área de Dourados e de $320 \mathrm{~L} \mathrm{ha}^{-1}$ na área de Ponta Porã. Amostras de solo nas profundidades de 0-10, $10-30,30-50,50-70$ e $70-100 \mathrm{~cm}$ foram coletadas para determinação dos resíduos de tiametoxam em ambas as áreas. Inicialmente, 20 amostras de solo $(0-5 \mathrm{~cm})$ foram coletadas ao acaso em cada área experimental, logo após aplicação do tiametoxam, para determinação da quantidade aplicada. Na área de Dourados as datas de amostragem foram 0, 15, 73 e 156 dias após aplicação e em Ponta Porã de 0, 41, 74 e 125 dias após a aplicação. Em cada data de amostragem quatro subparcelas (uma de cada quadrante) foram sorteadas para coleta das amostras, que consistiu na abertura de trincheiras até a profundidade de $1 \mathrm{~m}$. Amostras com aproximadamente $200 \mathrm{~g}$ de solo foram retiradas de cada profundidade e colocadas em sacos plásticos para armazenamento em freezer a $-20^{\circ} \mathrm{C}$, até o momento da análise. 
Tabela 1. Atributos químicos e físicos dos solos em D ourados e Ponta Porã, MS

\begin{tabular}{|c|c|c|c|c|c|}
\hline \multirow{2}{*}{$\begin{array}{l}\text { Prof. } \\
(\mathrm{cm})\end{array}$} & M.0. & Areia & Argila & \multirow{2}{*}{$\begin{array}{c}\mathrm{pH} \\
\mathrm{CaCl}_{2}\end{array}$} & \multirow{2}{*}{$\begin{array}{c}\rho \\
\left(\mathrm{g} \mathrm{cm}^{-3}\right)\end{array}$} \\
\hline & \multicolumn{3}{|c|}{$\left(\mathrm{g} \mathrm{kg}^{-1}\right)$} & & \\
\hline \multicolumn{6}{|c|}{ Latossolo Vermelho Distroférrico típico textura argilosa Dourados (MS) } \\
\hline $0-10$ & 33,4 & 245 & 630 & 4,8 & 1,02 \\
\hline $10-20$ & 29,6 & 229 & 663 & 4,4 & 1,11 \\
\hline $20-40$ & 22,7 & 212 & 697 & 4,5 & 1,14 \\
\hline $40-60$ & 16,9 & 195 & 713 & 4,6 & 1,11 \\
\hline $60-100$ & 11,3 & 195 & 713 & 4,6 & 1,10 \\
\hline \multicolumn{6}{|c|}{ Latossolo Vermelho Distrófico típico textura média Ponta Porã (MS) } \\
\hline $0-10$ & 17,5 & 743 & 213 & 4,9 & 1,42 \\
\hline $10-20$ & 16,5 & 743 & 230 & 4,9 & 1,51 \\
\hline $20-40$ & 13,8 & 726 & 230 & 4,3 & 1,49 \\
\hline 40-60 & 11,0 & 710 & 247 & 4,2 & 1,46 \\
\hline $60-100$ & 6,9 & 693 & 263 & 4,1 & 1,41 \\
\hline
\end{tabular}

A extração do tiametoxam nas amostras de solo foi baseada na metodologia de Urzedo et al. (2006a). Pesaram-se $100 \mathrm{~g}$ de solo e se adicionaram $200 \mathrm{~mL}$ de acetona em um Erlenmeyer de $500 \mathrm{~mL}$ com tampa, deixando-se agitar em mesa agitadora por 2 $\mathrm{h}$; em seguida, os frascos foram deixados em repouso durante $2 \mathrm{~h}$, de onde se retirou uma alíquota de $50 \mathrm{~mL}$ do sobrenadante, transferindo-a para um balão de fundo redondo para evaporação da acetona em evaporador rotativo. A fase aquosa remanescente foi transferida para um funil de separação, ao qual foi adicionado um volume de água destilada para alcançar o volume total de $20 \mathrm{~mL}$ da fase aquosa. O tiametoxam foi extraído da fase aquosa, por meio de três partições sucessivas com $20 \mathrm{~mL}$ de diclorometano, sendo a fase orgânica coletada em balão de fundo redondo. Após evaporação do diclorometano os resíduos foram transferidos para cromatoplacas de sílica gel $60 \mathrm{GF}_{254}(10$ x 20 x $0,05 \mathrm{~cm}$ ) e separados utilizando-se, como fase móvel, a mistura acetonitrila: diclorometano (1:3), sendo o fator de retenção do tiametoxam igual a 0,72 . O tiametoxam foi removido da sílica usando-se $20 \mathrm{~mL}$ de acetona, que foi eliminada no evaporador rotativo. Posteriormente, os resíduos foram transferidos para $1 \mathrm{~mL}$ da mistura acetonitrila:água ultrapura (2:8), a qual foi passada em filtro de $0,45 \mu \mathrm{m}$ antes de ser analisada. As determinações quantitativas do tiametoxam foram feitas por meio de cromatografia em fase líquida de alta eficiência - CLAE (HP - série 1100), com detector UV operando a $254 \mathrm{~nm}$. Utilizou-se uma coluna LiChrospher RP-18 (5 $\mu \mathrm{m}$ x 250 x $3 \mathrm{~mm})$ e, como fase móvel, acetonitrila:água ultrapura (2:8) com fluxo de $0,3 \mathrm{~mL} \mathrm{~min}^{-1}$. O padrão analítico do tiametoxam tinha pureza de $99 \%$. Teste de eficiência do método analítico revelou recuperação média de $88 \%$.

Utilizou-se o método da batelada para avaliação da sorção do tiametoxam (Lavorenti et al., 2003). As amostras foram coletadas nas profundidades de 0-30 e 50-70 cm em áreas vizinhas à do experimento de lixiviação nos solos de Dourados e Ponta Porã; em seguida, foram secadas ao ar, passadas em peneira de $1 \mathrm{~mm}$ de malha, pesados $2 \mathrm{~g}$ e acondicionadas em tubos de centrífuga de policarbono com tampas de plástico. Para cada profundidade foram feitas duas repetições às quais foram adicionados $5 \mathrm{~mL}$ de solução aquosa de tiametoxam

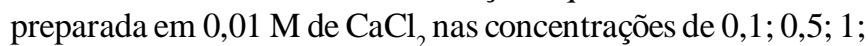
$5 \mathrm{e} 10 \mu \mathrm{g} \mathrm{mL}^{-1}$. Os tubos foram mantidos em mesa agitadora por $4 \mathrm{~h}$ e após este tempo foram submetidos a centrifugação a
$10.510 \mathrm{~g}$ durante $10 \mathrm{~min}$ a $25^{\circ} \mathrm{C}$. Foram coletados $2 \mathrm{~mL}$ do sobrenadante para análise por CLAE. Os dados de sorção do tiametoxam nas duas diferentes profundidades e solos foram ajustados ao modelo da isoterma de Freundlich, dado por:

$$
\mathrm{X}=\mathrm{K}_{\mathrm{F}} \cdot \mathrm{C}_{\mathrm{L}}^{\mathrm{N}}
$$

donde:

$\mathrm{X}$ - quantidade do tiametoxam adsorvida no solo, $\mu \mathrm{g} \mathrm{g} \mathrm{g}^{-1}$

$\mathrm{K}_{\mathrm{F}}$ - constante de equilíbrio de Freundlich, $\mathrm{mL} \mathrm{g}^{-1}$

$\mathrm{C}_{\mathrm{L}}$ - concentração do tiametoxam na fase líquida do solo, $\mu \mathrm{g} \mathrm{mL} \mathrm{m}^{-1}$

$\mathrm{N}$ - expoente do modelo de Freundlich

Para a degradação do tiametoxam em condições de laboratório, amostras de solo foram utilizadas nas profundidades de 0-30 e 50-70 cm, coletadas em áreas vizinhas à do experimento de lixiviação nos solos de Dourados e Ponta Porã. Inicialmente, as amostras foram secadas ao ar, passadas em peneira de $2 \mathrm{~mm}$ de malha e acondicionadas em copos de vidro correspondentes a $50 \mathrm{~g}$ de solo seco. Em cada copo foi adicionada água destilada em quantidade suficiente para atingir $80 \%$ da capacidade de campo de cada profundidade, determinada sob potencial mátricoigual a $0,1 \mathrm{~atm}$. Cada amostra foi fortificada com 10 e 11,75 $\mu \mathrm{g}$ de tiametoxam, nos solos de Dourados e Ponta Porã, respectivamente, por meio da aplicação de $1 \mathrm{~mL}$ de solução do padrão analítico em água destilada. Foram preparadas 10 amostras para cada profundidade e tipo de solo, correspondendo a 2 repetições para 5 datas de amostragem $(0,14,28,56$ e 224 dias no solo de Dourados e 0 , 15, 30, 45 e 60 dias no solo de Ponta Porã). Os copos contendo as amostras foram cobertos com papel laminado perfurados para permitir aeração e mantidos em incubadora tipo BOD com temperatura de $25 \pm 2{ }^{\circ} \mathrm{C}$, na ausência de luz. O controle da umidade em cada amostra foi mantido através da adição diária de água destilada, com auxílio de uma balança, até se atingir o peso (copo + solo + água) correspondente a $80 \%$ da capacidade de campo. O processo de extração e a quantificação dos resíduos de tiametoxam nas amostras de solo foram os mesmos descritos anteriormente. Os dados de degradação do tiametoxam nas diferentes profundidades e solos foram ajustados ao modelo de cinética de primeira ordem, após sua linearização, dada por:

$$
\ln \mathrm{C}=\ln \mathrm{C}_{0}-\mathrm{k} \cdot \mathrm{t}
$$

donde:

$\ln \mathrm{C}$ - logaritmo neperiano da quantidade remanescente do tiametoxam no solo, $\%$ da dose aplicada

$\ln \mathrm{C}_{0}$ - $\operatorname{logaritmo}$ neperiano da quantidade inicial aplicada ao solo, \%

k - coeficiente de degradação, dia ${ }^{-1}$

t - tempo de incubação, dias

Após estimativa de k a meia-vida (DT50), em dias, foi calculada por: 


$$
\mathrm{DT} 50=\frac{0,693}{\mathrm{k}}
$$

\section{RESULTADOS E DISCUSSÃO}

As isotermas de sorção de Freundlich para o tiametoxam nas profundidades de $0-30$ e $50-70 \mathrm{~cm}$ nos dois solos estudados são mostradas na Figura 1. Observa-se bom ajuste dos dados ao modelo de Freundlich para ambas as profundidades e solos, obtendo-se coeficientes de determinação $\left(R^{2}\right)$ superiores a 0,97 $(\mathrm{P}<0,05)$. Os valores das constantes de equilíbrio de Freundlich $\left(\mathrm{K}_{\mathrm{F}}\right.$ na Eq. 1) com seus erros padrões, foram iguais a $1,18( \pm 0,03)$ e $0,47( \pm 0,03) \mathrm{mL} \mathrm{g}^{-1}$ para as profundidades de 0-30 e $50-70 \mathrm{~cm}$, respectivamente, em Dourados e $0,40( \pm 0,08)$ e $0,15( \pm 0,01)$ $\mathrm{mL} \mathrm{g}^{-1}$ para as profundidades de $0-30 \mathrm{e} 50-70 \mathrm{~cm}$, respectiva-
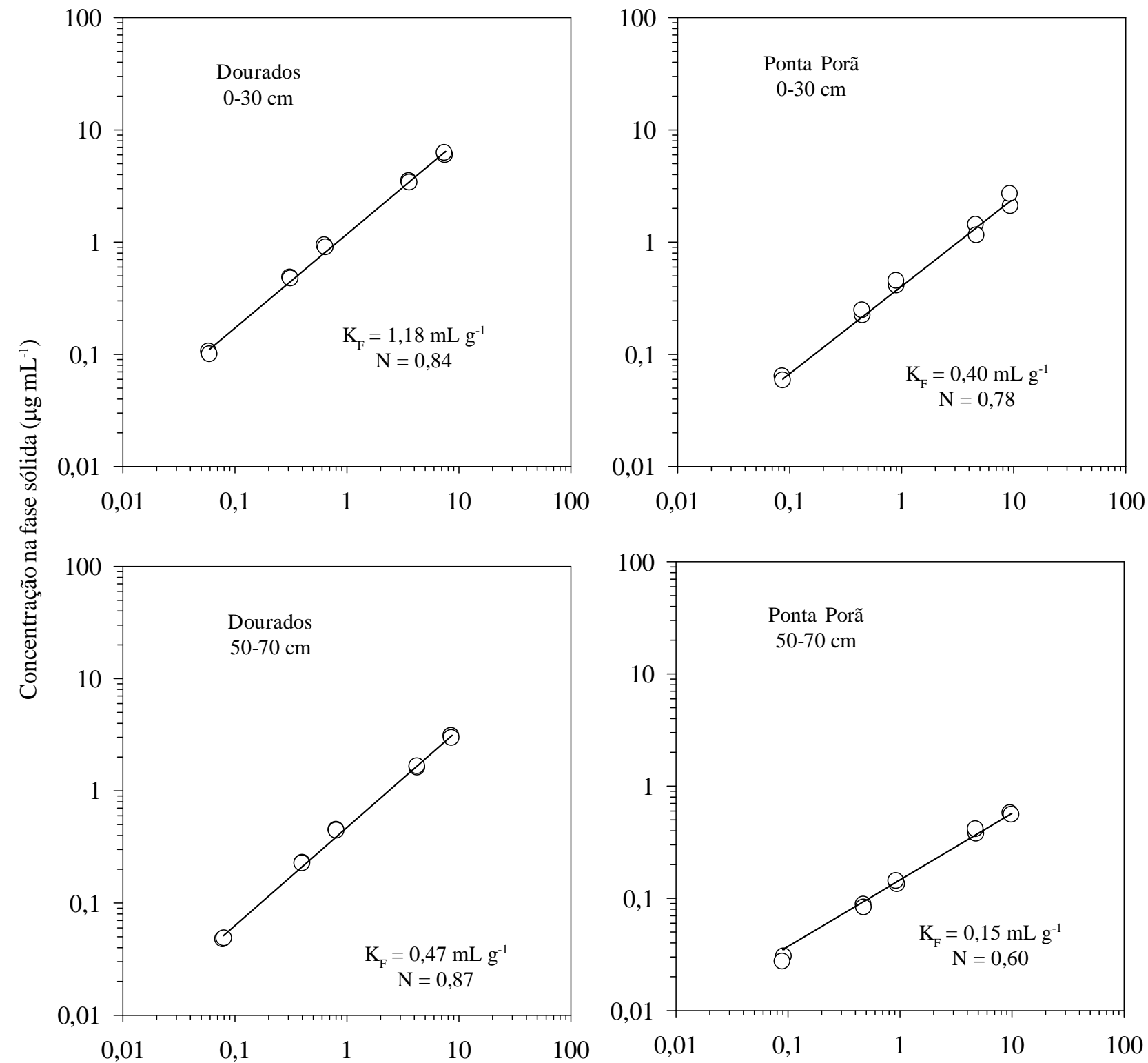

mente, em Ponta Porã. Os valores do expoente $\mathrm{N}$ do modelo de Freundlich (Eq. 1) variaram de 0,60 a 0,87 em ambas as profundidades e solos estudados, indicando uma diminuição no grau de sorção com o aumento na concentração do tiametoxam no solo. Os baixos valores de $\mathrm{K}_{\mathrm{F}}$ do tiametoxam nos dois solos e nas profundidades mostram sua baixa afinidade pela fase sólida dos solos estudados, sugerindo alta disponibilidade deste inseticida na solução do solo e grande potencial para lixiviação e/ou biodegradação. Urzedo et al. (2006b) e Banerjee et al. (2008) estudaram a sorção do tiametoxam em solos com diferentes teores de matéria orgânica e observaram alta correlação entre o teor de matéria orgânica e sua sorção. Assim, é possível que os menores valores de $\mathrm{K}_{\mathrm{F}}$ em Ponta Porã sejam devido aos menores teores de matéria orgânica encontrados neste solo (Tabela 1). Nesses solos se observa do valor de $\mathrm{K}_{\mathrm{F}}$ em função da profundidade, o que

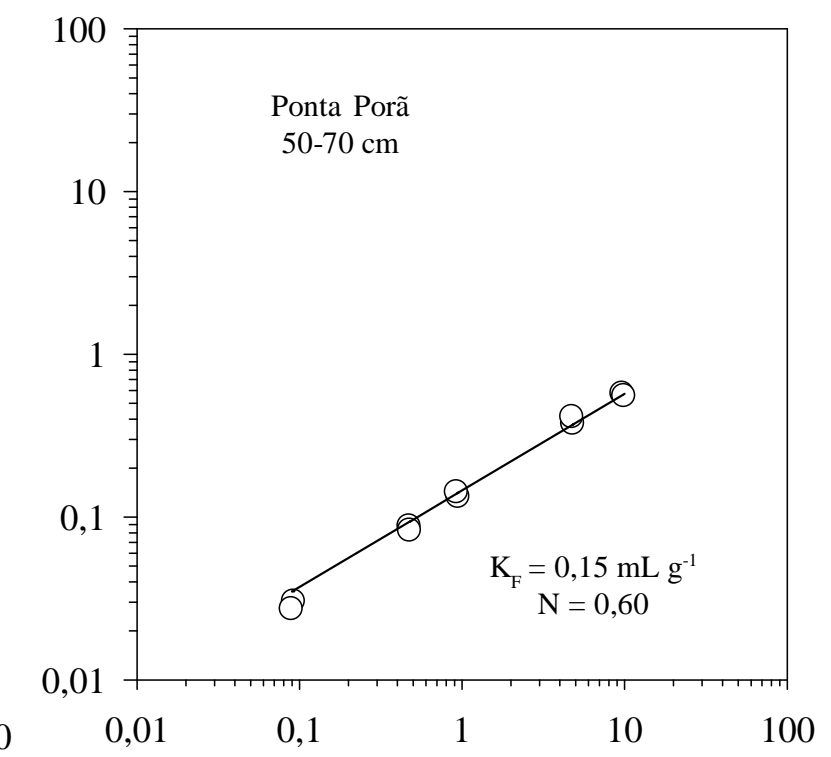

Concentração na fase líquida $\left(\mu \mathrm{g} \mathrm{mL} \mathrm{L}^{-1}\right)$

Figura 1. Isotermas de sorção do inseticida tiametoxam nas profundidades de 0-30 e 50-70 cm em D ourados e Ponta Porã, MS 
pode ser atribuído à diminuição dos teores de matéria orgânica, ao longo do perfil dos solos. Dividindo os valores de $\mathrm{K}_{\mathrm{F}}$ pelo teor de carbono orgânico dos solos obtêm-se os valores de $\mathrm{K}_{\mathrm{OC}}$ (Green \& Karickhoff, 1990), que podem ser usados para comparar diferentes estudos de sorção para um mesmo agrotóxico em diferentes solos. Os valores de $\mathrm{K}_{\mathrm{OC}}$ foram iguais a 7,11 e 5,75 $\mathrm{mL} \mathrm{g}^{-1}$ para as profundidades de 0-30 e 50-70 $\mathrm{cm}$ em Dourados e 4,34 e 2,89 $\mathrm{mL} \mathrm{g}^{-1}$ para as profundidades de 0-30 e 50-70 cm, em Ponta Porã. A diferença entre os valores de $\mathrm{K}_{\mathrm{OC}}$ entre os solos estudados sugere que a natureza da matéria orgânica e outros atributos dos solos podem influenciar a sorção do tiametoxam no solo. Carbo et al. (2007) observaram valores de $\mathrm{K}_{\mathrm{OC}}$ para o tiametoxam em dois diferentes solos de Primavera do Leste, MT, variando de 50 a $2321 \mathrm{~mL} \mathrm{~g}^{-1}$. Já Urzedo et al. (2006b) observaram, após estudar a sorção do tiametoxam em 12 diferentes solos na região de Lavras, $\mathrm{MG}$, valores de $\mathrm{K}_{\mathrm{OC}}$ variando de 13 a $81 \mathrm{~mL} \mathrm{~g}^{-1}$. Ambos os trabalhos de Carbo et al. (2007) e Urzedo et al. (2006b) relatam valores de $\mathrm{K}_{\mathrm{OC}}$ para o

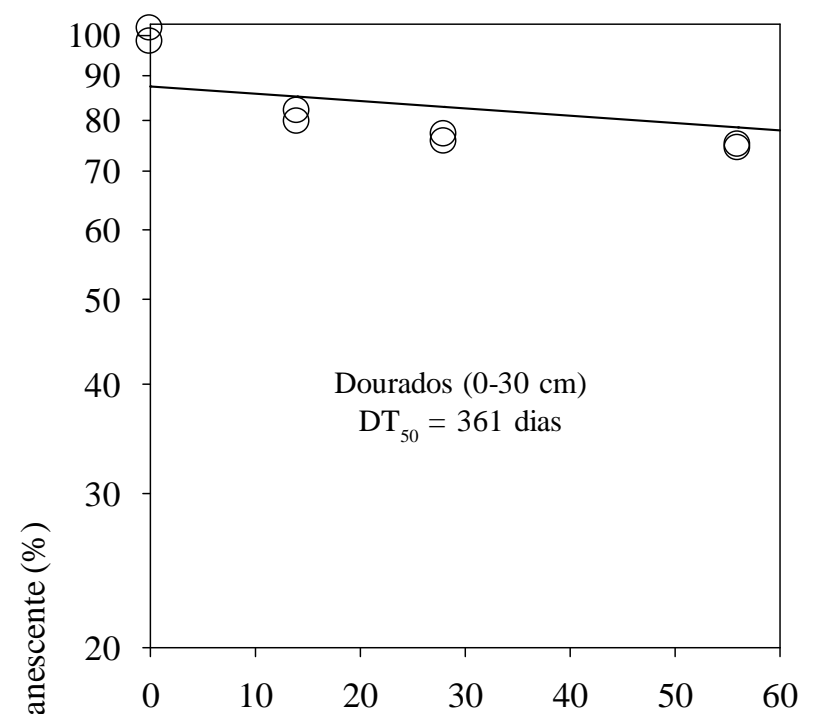

tiametoxam bem superiores aos encontrados neste estudo sugerindo que, embora a matéria orgânica seja o principal fator responsável pela sorção do tiametoxam em solos, sua natureza e polaridade podem influenciar o grau de sorção, ocasionando variabilidade nos valores de $\mathrm{K}_{\mathrm{OC}}$.

As quantidades remanescentes de tiametoxam em função do tempo nas profundidades de 0-30 e 50-70 cm nos dois solos estudados, são mostradas na Figura 2. Observa-se, em ambos os solos e nas profundidades que, de maneira geral, a degradação do tiametoxam revelou-se bastante lenta, com valores de meia-vida iguais a 361 e 618 dias em Dourados, nas profundidades de 0-30 e 50-70 cm, respectivamente e de 96 e 210 dias em Ponta Porã, nas profundidades de 0-30 e 50$70 \mathrm{~cm}$, respectivamente. Houve um bom ajuste dos dados $\left(\mathrm{R}^{2}\right.$ $>0,65 ; \mathrm{P}<0,05)$ do logaritmo neperiano da quantidade remanescente de tiametoxam (\%) em função do tempo (dias), para ambos os solos e profundidades, ao modelo de cinética de primeira ordem (Figura 2). Assim, a degradação do
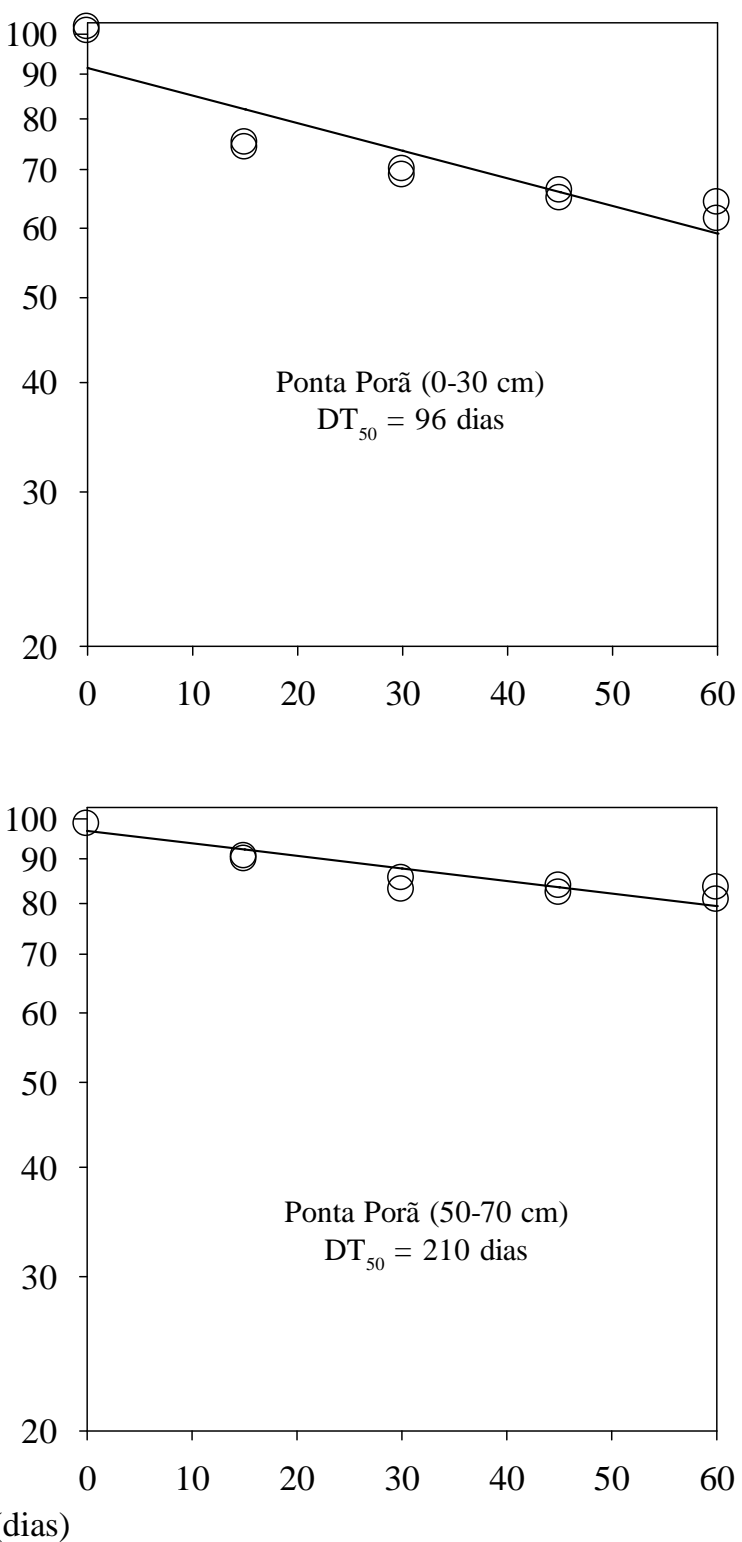

Figura 2. Cinética de degradação do inseticida tiametoxam em experimento de incubação $\left(25 \pm 2{ }^{\circ} \mathrm{C} ; 80 \%\right.$ da capacidade de campo e ausência de luz) nas profundidades de 0-30 e 50-70 cm, em D ourados e Ponta Porã, MS 
tiametoxam nas condições de laboratório estudadas seguiu aproximadamente uma cinética de degradação de primeira ordem, indicando uma meia-vida de degradação constante ao longo do tempo. A degradação mais lenta do tiametoxam em função da profundidade, em ambos os solos deve-se, possivelmente, à diminuição da densidade populacional de micro-organismos ao longo do perfil do solo e, em consequência, da atividade microbiana. Nota-se, para as duas profundidades, que em Ponta Porã a degradação do tiametoxam foi mais rápida quando comparada com Dourados. Como a sorção do tiametoxam foi menor em Ponta Porã, o fato sugere que este ficou mais disponível na solução do solo para ser degradado. Na camada superficial $(0-30 \mathrm{~cm})$ se constata, em ambos os solos, uma degradação mais rápida do tiametoxam entre a aplicação e a primeira amostragem (Figura 2) quando comparada com as outras datas de amostragem. Uma diminuição da taxa de degradação do tiametoxam após a primeira data de amostragem pode, provavelmente, ser atribuída à fração do composto fortemente adsorvida e que estaria menos acessível para degradação (Laabs et al., 2000; Gupta et al., 2008). Como consequência, um modelo de degradação bifásico poderia ser mais adequado para descrever esse tipo de comportamento. No entanto, optou-se por forçar o ajuste dos dados de degradação ao modelo de cinética de primeira ordem com o objetivo de subsidiar o uso de simuladores de lixiviação de agrotóxicos em solos brasileiros que necessitem desses dados de entrada e apenas consideram, para descrever a degradação, o modelo de cinética de primeira ordem. É oportuno ressaltar que, como implicação dessa decisão, o uso de um modelo de cinética de primeira ordem para a camada superficial $(0-30 \mathrm{~cm})$ leva a subestimar a estimativa da meia-vida nos primeiros dias e uma superestimativa no período restante. Urzedo et al. (2006a) observaram valores de meia-vida para o tiametoxam entre 117 e 301 dias em solos de 0-20 cm de profundidade na região de Lavras, MG, mostrando, assim, a alta persistência desse composto. De acordo com a classificação do IBAMA (1990) e com base nos valores de meia-vida do tiametoxam encontrados na camada superficial $(0-30 \mathrm{~cm})$, este pode ser classificado como medianamente persistente a persistente, nas condições estudadas.

Os estudos de campo revelaram que a quantidade média recuperada de tiametoxam logo após a aplicação (0 dia), na profundidade de 0-100 $\mathrm{cm}$ em Dourados, foi de $0,20 \mathrm{~kg} \mathrm{ha}^{-1} \mathrm{e}$, para Ponta Porã, de 0,28 kg ha ${ }^{-1}$ (Figura 3). Essas quantidades correspondem a 77 e $103 \%$ das doses aplicadas para Dourados e Ponta Porã, respectivamente. Nas datas de amostragem seguintes, as quantidades remanescentes de tiametoxam no perfil do solo $(0-100 \mathrm{~cm})$, foram iguais a 32,26 e $10 \%$ aos 15,73 e 156 dias após aplicação em Dourados e iguais a 33, 31 e 6\% aos 41, 74 e 125 dias após aplicação, em Ponta Porã (Figura 3).

Para ambos os solos e condições climáticas avaliadas observa-se uma rápida dissipação do tiametoxam logo após a aplicação, equivalente a $68 \%$ da dose após 15 dias da aplicação em Dourados e 67\% após 41 dias da aplicação em Ponta Porã. Importante ressaltar que se observou uma dissipação mais intensa do tiametoxam no campo do que em laboratório. Por exemplo, a meia-vida estimada do tiametoxam a $25^{\circ} \mathrm{C}$ na
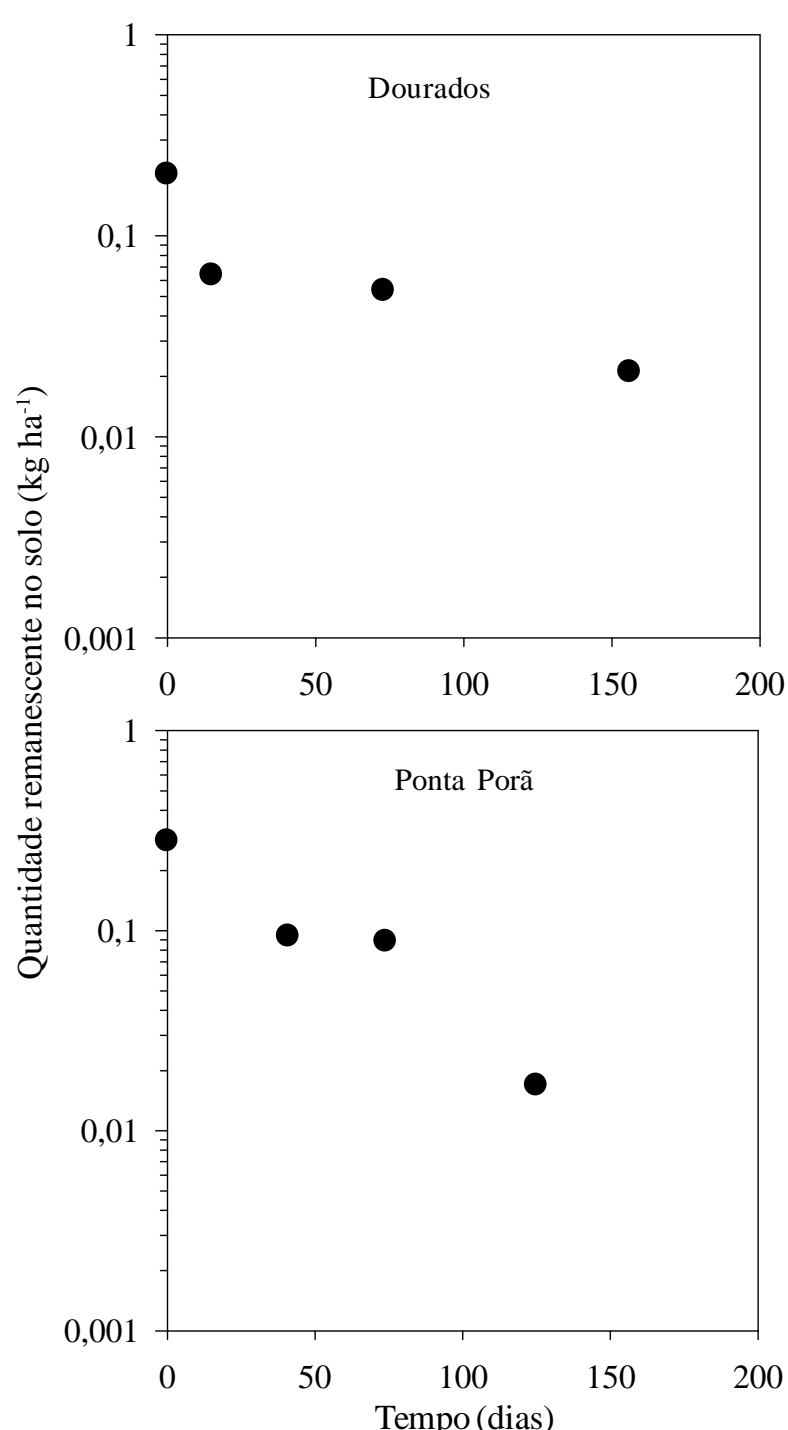

Figura 3. Q uantidade remanescente média do inseticida tiametoxam na profundidade de 0-100 cm, após aplicação no campo, em D ourados e Ponta Porã, MS

profundidade de 0-30 $\mathrm{cm}$ foi de 96 dias, sugerindo que se esperaria, aos 96 dias após aplicação, uma recuperação de aproximadamente $50 \%$ da dose aplicada. No entanto, já aos 41 dias após aplicação no campo observou-se uma quantidade remanescente no perfil do solo de apenas $33 \%$ da dose aplicada. Discrepâncias entre os valores de meia-vida de agrotóxicos obtidos em laboratório e em condições de campo têm sido relatadas na literatura, com tendência geral dos valores de laboratório serem superiores aos de campo. Beulke et al. (2000) sugerem que as principais razões para essas discrepâncias estão relacionadas às diferenças das condições do solo no laboratório e no campo como, por exemplo: (i) diminuição da biomassa microbiana nos experimentos com solos incubados em laboratório e (ii) uso de condições estáticas de temperatura e umidade nos experimentos em laboratório. Posteriormente, Beulke et al. (2005) realizaram um estudo para avaliar a influência da flutuação da umidade e da temperatura, do tamanho dos agregados do solo e do regime de fluxo da água na degradação de dois agrotóxicos em condições de laboratório, e concluíram que não houve diferença nos valores de meia-vida ao 
consideraram esses fatores estáticos ou dinâmicos. Assim, os autores presumem que as condições estáticas assumidas em estudos de degradação de agrotóxicos em laboratório, não são consideradas limitações sérias quando se deseja caracterizar a degradação no campo, baseando-se em estudos de laboratório. Considerando que a dissipação mais rápida do tiametoxam nos solos estudados não pode ser explicada por uma lixiviação abaixo dos $100 \mathrm{~cm}$ de profundidade (Figura
4) nem pelos valores de meia-vida obtidos em laboratório, especula-se que essa dissipação mais intensa no campo esteja relacionada às maiores temperaturas do solo no período experimental quando comparadas com as do experimento de incubação no laboratório $\left(25^{\circ} \mathrm{C}\right)$, fotólise (Maienfisch et al., 2001), absorção pelas raízes das plantas de soja e volatilização devido às altas temperaturas e umidade na superfície do solo logo após a aplicação.

Concentração de tiametoxam no solo $\left(\mathrm{mg} \mathrm{dm}^{-3}\right)$
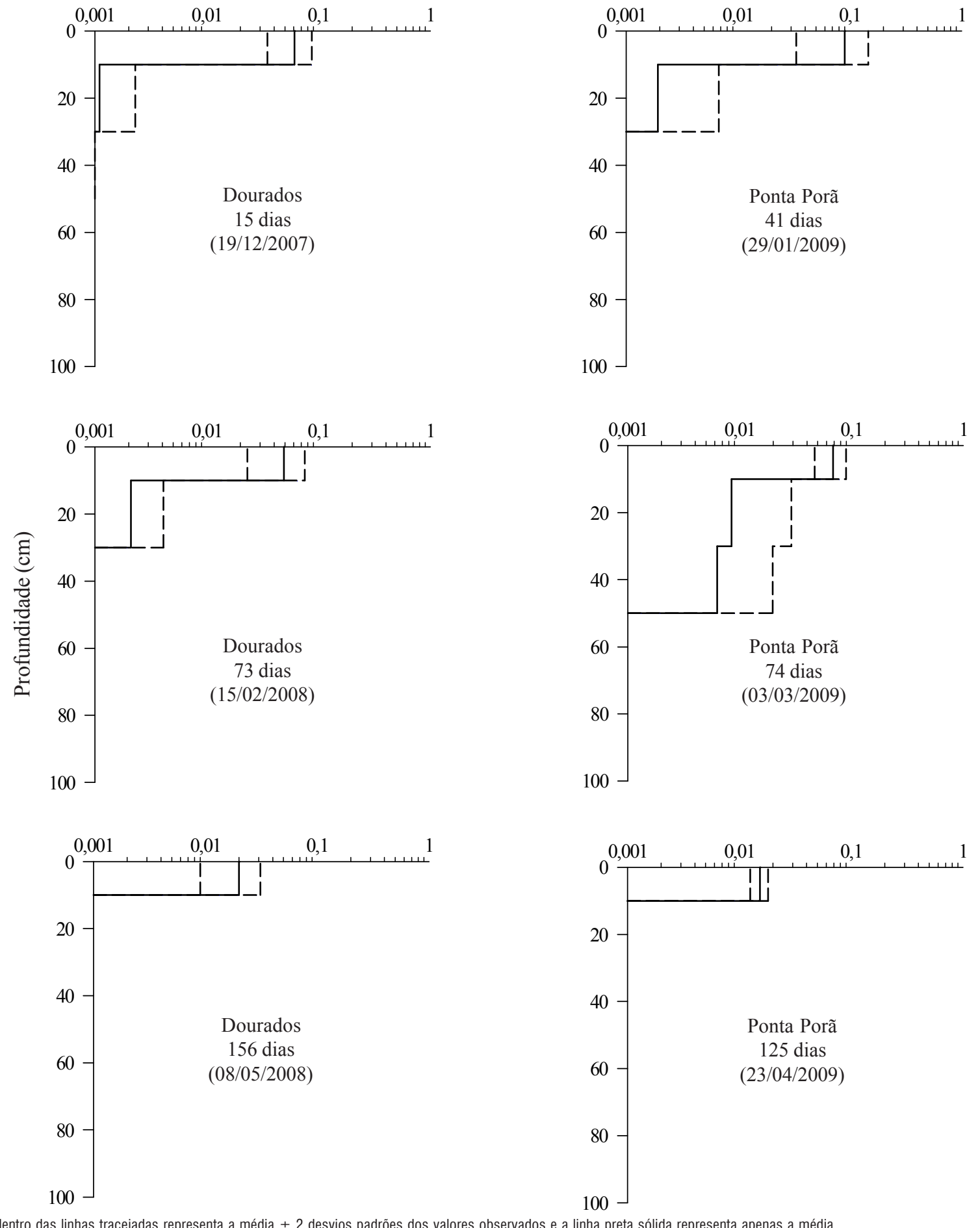

Obs.: A área dentro das linhas tracejadas representa a média \pm 2 desvios padrões dos valores observados e a linha preta sólida representa apenas a média

Figura 4. Perfis de concentração do inseticida tiametoxam nas diferentes datas de amostragem em Dourados e Ponta Porã, MS 


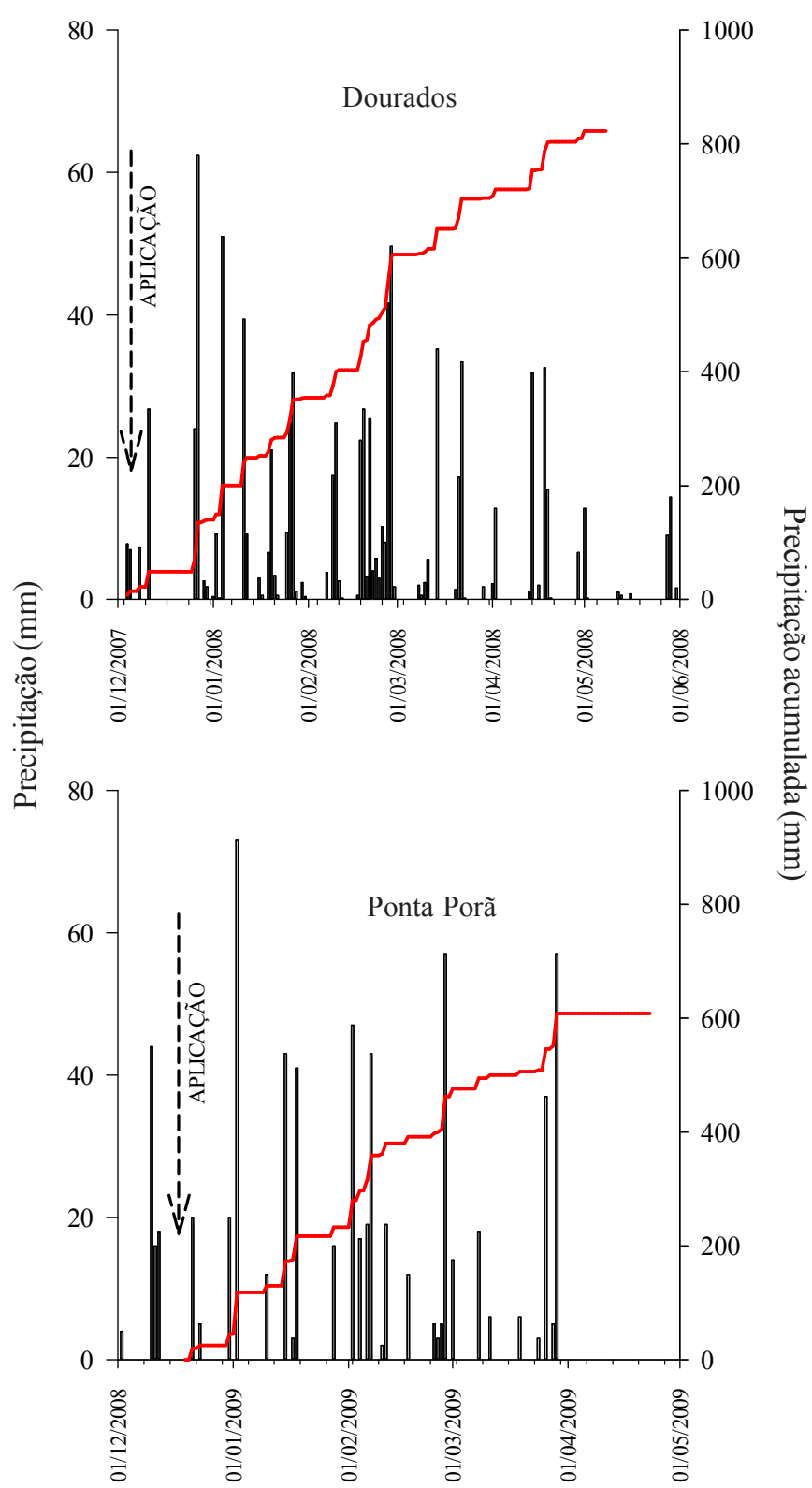

Figura 5. Precipitação diária (barras verticais) e acumulada (linha vermelha) nas áreas experimentais de Dourados e Ponta Porã, MS

As concentrações do tiametoxam ao longo do perfil dos solos em Dourados e Ponta Porã nas diferentes datas de amostragem, são mostradas na Figura 4. Observa-se que, de maneira geral, a lixiviação do tiametoxam ficou restrita aos 50 $\mathrm{cm}$ de profundidade para ambos os solos, mesmo que não tenha ultrapassado os $30 \mathrm{~cm}$ em Dourados. Em referência a Dourados, a quantidade acumulada de precipitação até os 15 dias após aplicação (primeira amostragem após aplicação) foi de $49 \mathrm{~mm}$, em que grande parte do tiametoxam ficou restrita aos primeiros $10 \mathrm{~cm}$; já em Ponta Porã a quantidade acumulada de precipitação até os 41 dias após aplicação foi de $233 \mathrm{~mm}$ e grande parte do tiametoxam também ficou restrita aos primeiros $10 \mathrm{~cm}$ de profundidade; verifica-se, então, que embora em Ponta Porã a precipitação acumulada tenha sido quase cinco vezes superior à de Dourados entre a aplicação e a primeira amostragem, não se observou grande diferença na lixiviação do tiametoxam entre os solos. Importante mencionar que em ambos os solos estudados existe alta macroporosidade média no perfil do solo (26 e 15\% para Dourados e Ponta Porã, respectivamente).

Diante disto se pressupõe que grande parte da água que infiltra nesses solos ocorre através dos macroporos. Assim, devido à baixa sorção do tiametoxam nos solos estudados (baixos valores de $\mathrm{K}_{\mathrm{OC}}$ ), alta macroporosidade nos solos e altas precipitações acumuladas durante o período experimental iguais a $823 \mathrm{~mm}$ para Dourados e $608 \mathrm{~mm}$ para Ponta Porã (Figura 5), esperava-se uma lixiviação maior do tiametoxam em condições de campo. Considerando que grande parte da água que infiltrou nesses solos ocorreu via macroporos, especula-se que ocorreu um contato limitado entre a água e a matriz do solo (microporos). Supondo que grande parte do tiametoxam estava presente ou protegido no interior dos agregados e/ou microporos, o fluxo de água que ocorreu preferencialmente pelos macroporos, não permitiu o equilíbrio das concentrações.

Assim, a água que infiltrava transportava apenas uma pequena quantidade do tiametoxam para as camadas mais profundas. Especula-se que houve diminuição da lixiviação do tiametoxam com a presença do fluxo preferencial da água via macroporos. Resultados semelhantes foram obtidos por Larsson \& Jarvis (1999) em solos suecos, onde o fluxo preferencial da água diminuiu a lixiviação do herbicida bentazona. Castro et al. (2008) observaram alta lixiviação do tiametoxam em dois solos da região de Lavras, $\mathrm{MG}$, utilizando macrolisímetros de até $180 \mathrm{~cm}$ de profundidade sob condição de chuva natural e sem vegetação. Os resultados deste trabalho divergem dos obtidos por Castro et al. (2008) o que será atribuído, possivelmente, à razão explicitada acima e também à maior evapotranspiração em virtude da presença das plantas, absorção do tiametoxam pelas raízes e tipo de solo, todos esses fatores diminuindo a lixiviação nas condições estudadas.

\section{CONCLUSÕES}

1. O tiametoxam revelou-se como agrotóxico com baixa sorção no perfil de ambos os solos estudados.

2. O tiametoxam apresentou-se como agrotóxico persistente (meia-vida entre 96 e 618 dias) no experimento de incubação em condições de laboratório, para ambos os solos.

3. Houve uma dissipação mais rápida do tiametoxam nos experimentos a campo, nos primeiros dias após a aplicação, em relação à dissipação inicial observada em laboratório, nos dois solos estudados.

4. Embora o tiametoxam tenha apresentado pouca afinidade e alta persistência no solo, sua lixiviação nas condições edafoclimáticas estudadas foi pequena $(<50 \mathrm{~cm}$ de profundidade).

\section{Agradecimentos}

Os autores agradecem o suporte financeiro da Fundect (109/ 06 e 034/07), International Foundation for Science (IFS - Grant W/4208-1) e CNPq (471517/2007-0). 


\section{LITERATURA CITADA}

Andrei, E. Compêndio de defensivos agrícolas. 7.ed. São Paulo: Organizações Andrei, 2005. 1141p.

Banerjee, K.; Patil, S. H.; Dasgupta, S.; Oulkar, D. P.; Adsule, P. G. Soprtion of thiamethoxam in three Indian soils. Journal of Environmental Science and Health Part B, v.43, p.151-156, 2008.

Bergström, L.; Börjesson, E.; Stenström, J. Laboratory and lysimeter studies of glyphosate and aminomethylphosphonic acid in a sand and clay soil. Journal of Environmental Quality, v.40, p.98-108, 2011.

Beulke, S.; Dubus, I. D.; Brown, C. D.; Gottesbüren, B. Simulation of pesticide persistence in the field on the basis of laboratory data - A review. Journal of Environmental Quality, v.29, p.1371-1379, 2000.

Beulke, S.; van Beinum, W.; Brown, C. D.; Mitchell, M.; Walker, A. Evaluation of simplifying assumptions on pesticide degradation in soil. Journal of Environmental Quality, v.34, p.1933-1943, 2005.

Boesten, J. J. T. I. Simulation of pesticide leaching in the field and in zero-tension lysimeters. Vadose Zone Journal, v.6, p.793-804, 2007.

Carbo, L.; Martins, E. L.; Dores, E. F. G. C.; Spadotto, C. A.; Weber, O. L. S.; De-Lamonica-Freire, E. M. Acetamiprid, carbendazin, diuron and thiamethoxam sorption in two Brazilian tropical soils. Journal of Environmental Science and Health Part B, v.42, p.499-507, 2007.

Castro, N. R. A.; Rigitano, R. L. O.; Lima, J. M.; Guerreiro, M. C. Lixiviação do inseticida thiamethoxam em macrolisímetros de duas classes de solo. Ciência e Agrotecnologia, v.32, p.1818-1823, 2008.

Chaim, A.; Valarini, P. J.; Oliveira, D. A.; Morsoleto, R. V.; Pio, L. C. Avaliação de perdas de pulverização em culturas de feijão e tomate. Jaguariúna: Embrapa Meio Ambiente, 1999, 29 p. Boletim de pesquisa, 2.

Farenhorst, A.; McQueen, D. A. R.; Saiyed, I.; Hilderbrand, C.; Li, S.; Lobb, D. A.; Messing, P.; Schumacher, T. E.; Papiernik, S. K.; Lindstrom, M. J. Variations in soil properties and herbicide sorption coefficients with depth in relation to PRZM (pesticide root zone model) calculations. Geoderma, v.150, p.267-277, 2009.

Green, R. E.; Karickhoff, S. W. Sorption estimates for modeling. In: Cheng, H. H. Pesticides in the soil environment: Process, impacts and modeling. Madison: SSSA, Chapter 4, 1990. p.79-101.
Gupta, S.; Gajbhiye, V. T.; Gupta, R. K. Soil dissipation and leaching behavior of a neonicotinoid insecticide thiamethoxam. Bulletin of Environmental Contamination and Toxicology, v.80, p.431-437, 2008.

IBAMA - Instituto Brasileiro do Meio Ambiente e dos Recursos Renováveis. Manual de testes para avaliação da ecotoxicidade de agentes químicos. 2.ed. Brasília: IBAMA, 1990.351p.

Laabs, V.; Amelung, W.; Pinto, A.; Altstaedt, A.; Zech, W. Leaching and degradation of corn and soybean pesticides in an Oxisol of the Brazilian Cerrados. Chemosphere, v.41, p.1441-1449, 2000.

Larsson, M. H.; Jarvis, N. J. Evaluation of a dual-porosity model to predict field-scale solute transport in a macroporous soil. Journal of Hydrology, v.215, p.153-171, 1999.

Lavorenti, A.; Prata, F.; Regitano, J. B. Comportamento de pesticidas em solos: fundamentos. Tópicos em Ciência do Solo, v.3, p.291-334, 2003.

Maienfisch, P.; Angst, M.; Brandl, F.; Fischer, W.; Hofer, D.; Kayser, H.; Kobel, W.; Rindlisbacher, A.; Senn, R.; Steinemann, A.; Widmer, H. Chemistry and biology of thiamethoxam: a second generation neonicotinoid. Pest and Management Science, v.57, p.906-913, 2001.

Santos, H. G.; Jacomine, P. K. T.; Anjos, L. H. C.; Oliveira, V. A.; Oliveira, J. B.; Coelho, M. R.; Lumbreras, J. F.; Cunha, T. J. F. Sistema brasileiro de classificação de solos. 2.ed. Rio de Janeiro: Embrapa Solos, 2006. 306p.

Scorza Júnior, R. P. Pesticidas, agricultura e recursos hídricos. Dourados: Embrapa Agropecuária Oeste, 2006. 9p. Circular Técnica, 12

Pinheiro, A.; Moraes, J. C. S.; Silva, M. R. Pesticidas no perfil do solo em áreas de plantação de cebolas em Ituporanga, SC. Revista Brasileira de Engenharia Agrícola e Ambiental, v.15, p.533-538, 2011.

Urzedo, A. P. F. M.; Rigitano, R. L. O.; Guerreiro, M. C.; Castro, N. R. A. Dissipação do inseticida tiametoxam em solos da região de Lavras-MG. Pesticidas: Revista de Ecotoxicologia e Meio Ambiente, v.16, p.31-38, 2006a.

Urzedo, A. P. F. M.; Rigitano, R. L. O.; Lima, J. M.; Castro, N. R. A. Sorção do inseticida tiametoxam em amostras de solos da região de Lavras - MG. Pesticidas: Revista de Ecotoxicologia e Meio Ambiente, v.16, p.71-80, 2006 b.

Verschoor, A. J.; Boesten, J. J. T. I.; Leistra, M.; van der Linden, A. M. A.; Linders, J. B. H. J.; Pol, J. W. W. Evaluation of pesticide leaching in lysimeter and field studies, parent substances. Bilthoven: RIVM, 2002. 44p. Report 601506007. 